\title{
A New Species of Bruchidius (Coleoptera: Chrysomelidae: Bruchinae) from Albizia in Northern Thailand and a Review of Bruchidius Group 5
}

\author{
Midori Tuda \\ Institute of Biological Control, Faculty of Agriculture, Kyushu University, Fukuoka 812-8581, Japan
}

Short title: New Bruchidius Beetle from Thailand

Field: Taxonomy

\section{Correspondence:}

Tel: +81-92-642-3038, FAX: +81-92-642-3040

E-mail: tuda@grt.kyushu-u.ac.jp

\begin{abstract}
A new species, Bruchidius paicus (Insecta, Coleoptera) reared from the seeds of a leguminous tree, Albizia lebbeck (Fabaceae: Mimosoideae: Ingeae), is described from Northern Thailand. Inspection of genital and external morphological traits of B. paicus revealed that the new species belongs to Bruchidius Group 5 (sensu Châjô, 1937). The definition of Group 5 is reviewed based on both external and genital morphology. Further comparison of the group to molecular Clade I of Bruchidius (sensu Kergoat, 2007a) indicates the two groups correspond to each other.
\end{abstract}

Keywords: Asia, Bruchidae, seed predator, Bruchidius terrenus, Leguminosae 


\section{INTRODUCTION}

Bruchidius is a heterogeneous genus within Bruchinae (Coleoptera: Chrysomelidae) (Borowiec, 1987). Recent integration of knowledge on Bruchidius revealed that there are indeed several phylogenetic groups within Bruchidius that are associated with host-plant taxonomic groups as in other bruchine genera, suggesting a certain conservatism in host-plant use (Kergoat et al., 2005, 2007a; Delobel and Delobel, 2006). Chûjô (1937) defined six taxonomic groups within Bruchidius inhabiting Far East Asia, according to external morphology. Among these, Group 5 is represented by Bruchidius terrenus (Sharp) and Bruchidius urbanus (Sharp), both of which utilize the mimosoids Albizia and Acacia as their host plants (Tuda et al., unpublished). The extent to which Chûjô’s definition of Group 5 can be applied to bruchines inhabiting regions outside the Far East, and the host-utilization pattern of Group 5, were unknown.

Here, I report a new species of Bruchidius reared from the seeds of an Albizia species in Northern Thailand. Inspection of external and internal morphology reveals that the new species belongs to Bruchidius Group 5. The taxonomic definition of Group 5 is extended based on both external and genital morphology, in reference to the present species and other recently obtained species in the group.

\section{MATERIALS AND METHODS}

The specimens studied were adults that emerged from the seeds of Albizia lebbeck (L.) Benth. collected in Chiang Mai and Mae Hong Son Provinces, Thailand, in mid-December 2004. The genitalia of males were cleaned by incubating in warmed $5 \% \mathrm{KOH}$ solution and, after washing, mounted in glycerol. Specimens of the genitalia and external morphology were examined using a digital microscope (VHX-600, Keyence).

I compared these specimens with my specimens of the following Bruchidius species that utilize Albizia species in Northern Thailand: Bruchidius aureus Arora, B. flavovirens Arora, $B$. lineolatus Arora, B. pygomaculatus Arora, B. saundersi (Jekel), B. sparsemaculatus Pic, B. terrenus (Sharp), B. urbanus (Sharp), and B. variegata Arora. In addition, I compared my material with the drawings by Arora $(1977,1980)$ of male genitalia of Indian Bruchidius species associated with Albizia and by Delobel (2006) of related African Bruchidius species associated with caesalpinioids: B. amarae Arora, B. bangalorensis Arora, B. brunnetashii Arora, B. endotubercularis Arora, B. solanensis Arora, B. badjii Delobel, B. biloboscutus Pic, and B. lerui Delobel.

The external morphological traits of Bruchidius Group 5 defined by Chûjô (1937) are as follow: body not large (vs. Group 1 and Megabruchidius [c.f. Tuda and Morimoto, 2004]), spindle 
shaped, flat especially on dorsal side, pygidium slightly slanted; antennae weakly serrate, shorter than half body length (vs. Group 2); lateral margins of pronotum slightly round yet without any denticles (vs. Group 1); elytral base not extremely inflated laterally (vs. Conicobruchus); hind tibia apically with small spines, tibial ventral mucro not extremely longer than other spines (vs. Group 3 and Megabruchidius); tarsal segment 1 slightly bent, longer than summed length of all other apical segments (vs. Conicobruchus).

\section{TAXONOMY}

Bruchidius paicus sp. nov.

(Figs. 1-5)

\section{Type material}

Holotype. Male (0470/1, Kyushu University), Mae Chaem, Chiang Mai Province, Thailand (18 ${ }^{\circ} 30 \mathrm{~N}, 98^{\circ} 21^{\prime} \mathrm{E}$, altitude $450 \mathrm{~m}$ ). Pods collected, 17.xii.2004 (Tuda and Buranapanichpan, 0470), BKF (Forest Herbarium, National Park, Wildlife and Plant Conservation Department, Ministry of Natural Resources and Environment, Bangkok, Thailand).

Paratypes. Three females, same data as for holotype. One male, one female, Pai, Mae Hong

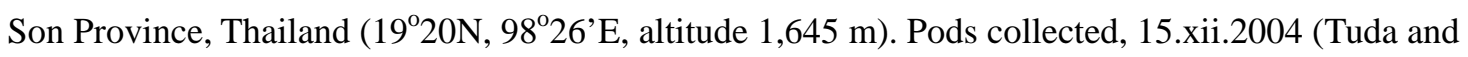
Buranapanichpan, 0435), BKF.

\section{Description}

Body spindle-shaped, flat; pygidium, apical two thirds slanted (Fig. 1).

Integument: Yellowish brown to dark brown or black. Head dark brown to black. Antennae yellowish light brown. Pronotum dark brown to black. Elytra light brown, with intervals 1-3(5), basal and posterior parts, dark brown to black. Fore and mid legs yellowish light brown, except base of mid femora dark brown. Hind legs dark brown.

Vestiture: White to yellowish setae. Head sparsely covered with yellowish white setae. Pronotum covered with yellowish white setae, denser in central posterior area. Ventral side covered sparsely with yellowish white setae, densely in lateroventral areas. Pygidium covered almost uniformly with yellowish white setae, slightly denser in centrobasal area and in vertical central line. Elytral intervals 1, 2, and 10 covered uniformly with pale white and yellowish setae, intervals 3 and 5 covered with white setae intermitted by yellowish and dark-colored setae, middle part of intervals 4, 6 , and 8 covered uniformly with yellowish and pale white setae, intervals 7 and 9 with pale white or yellowish setae intermitted by areas covered with dark-colored setae (Fig. 1). Dark-colored setae 
on intervals 5 and 7 uniformly white in some individuals. Scutellum covered with yellowish white setae.

Head short, densely punctate, eye diameter $0.29-0.38 \mathrm{~mm}$, about 1.6 of interocular length, interocular line moderately distinct. Antenna almost of the same shape and length in both sexes, about 1.0-1.2 mm long, reaching slightly beyond posterior angles of pronotum. Antennal segments 1 and 2 subcylindrical, 3 widened at apex, 4-9 serrate, wider than long, 10 oval (Fig. 2). Pronotum weakly campanulate, length about 1.7 times width, widest at apex, densely punctate, lateral margins without any denticles. Scutellum roundish, slightly bifid posteriorly. Elytra only slightly (1.02 times) longer than combined width, widest in middle, dorsal side even, intervals 3 and 5 broader than neighboring intervals, two tubercules on elytral striae 3 and 4, intervals densely punctate. Pygidium about as long as wide. Hind femora bicarinate below, length about 2.6 times width, ventral margin of inner carina with two denticles followed by a preapical spine (Fig. 3). Hind tibial spine about twice as long as lateral coronal spinule. Hind tarsal segment 1 , longer than the remaining segments combined, about 0.7 times of length of hind tibia.

Male: Ventrite 1 of male without a central depression. Median lobe of genitalia, short, stout, 4.8 times as long as wide at middle, apically dome-shaped, with ventral valve, dull triangular, apically not acute, carrying about 10 setae (Fig. 4). Endophallus with numerous, scattered fine spines, pouch-like part in middle, lined with numerous sclerotized denticles in distal half from apex. Lateral lobes separated to 0.7 of their length, apically widened, curve inward, lateroapically with about 15 setae (Fig. 5).

Female: Body larger, integument color lighter than male. Antennae relative to body length shorter than male. Pygidium length/width ratio slightly larger than male, without depressions.

Size: Length 2.2-3.3 mm from pronotum to elytra; width 1.5-2.2 mm.

Host plant: Albizia lebbeck, confirmed by the emergence of B. paicus adults from the seeds collected. This plant species is probably native to tropical mainland Asia (Nielsen, 1985).

Distribution: Northern Thailand.

\section{Remarks}

This species is similar to Bruchidius sparsemaculatus Pic. in general appearance and structures of antennae and genitalia, but has smaller body; brownish integument in lateral areas of elytra, contrasting with uniformly black integument of B. sparsemaculatus; white setae absent in lateroposterior area of elytra; distinctively shorter hind tibial spine; and apically narrower lateral lobes with less-sclerotized lateroapical areas. Bruchidius paicus sp. nov. belongs to Group 5 (see Discussion). 


\section{DISCUSSION}

Bruchidius paicus was found only twice in the mountainous areas in Chiang Mai in spite of our continuous investigations since 1998 of leguminous trees and herbs in Northern Thailand, north to Mae Sai, south to Lampang, west to Mae Hong Son, and east to Thoen. In contrast, in other areas and from other Albizia species, several Bruchidius species in Group 5, excepting B. paicus, emerged, indicating the limited geographical distribution and high host-plant specificity of B. paicus (Tuda, Tateishi, Niyomdham, Buranapanichpan, Pajni, Tewari, Murugan, Toquenaga, Ishihara, Chou, and Morimoto, unpublished).

All the Albizia-associated Bruchidius species whose specimens I examined in the present study and African caesalpinioid-feeding Bruchidius that are positioned in the same molecular phylogenetic clade with Bruchidius terrenus share external morphological traits of Group 5 defined for Far-East-Asian Bruchidius by Chûjô (1937) (c.f. drawings made by Morimoto [1990b] and Delobel [2006], and Figs. 4 and 5; see Materials and Methods for species examined). The genital characteristics shared by the above species in Group 5 are as follows: median lobe, short, stout, apically dome-shaped; ventral valve dull triangular to roundish, not acute apically; endophallus with small denticles, without distinguished sclerotized plates or elongated spines; lateral lobes cleft to 0.6-0.8 total length, each lobe not too slender, apically widened and incurved. Following this genital definition of Group 5, additional Bruchidius species identified as members of this group, judging from the drawings of genitalia made by Arora $(1977,1980)$, are Bruchidius amarae Arora, $B$. bangalorensis Arora, B. brunnetashii Arora, B. endotubercularis Arora, and B. solanensis Arora.

I reviewed Group 5, with the above additional members. Group 5 includes species with a significantly large body, such as Bruchidius aureus, B. bangalorensis, B. saundersi, B. sparsemaculatus, and B. variegata, extending Chûjô’s (1937) recognition that this morphological group is characterized by small body size. The large body size of the South-Asian bruchines is probably due to the availability of large-seeded Albizia in this area, because most bruchine beetles utilize single seeds and therefore their body size tends to correlate with the seed size of their host plants (Tuda, Szentesi, and Jermy, unpublished).

Recent integration of knowledge on Bruchidius revealed that there are indeed several phylogenetic groups within this genus that are associated with the taxonomic groups of their host plants, as in other bruchine genera (Jermy and Szentesi, 2003; Tuda et al., 2005, 2006; Tuda, 2007; Kergoat et al., 2007b), suggesting a certain conservatism in host-plant use (Kergoat et al., 2005, 2007a; Delobel and Delobel, 2006). Clade I, one of the molecular phylogenetic clades within Bruchidius (Clade I sensu Kergoat et al., 2007a), utilizes as larval hosts the seeds of Asian and African leguminous trees of the genera Albizia and Acacia (Fabaceae: Mimosoideae), with a few exceptional species utilizing or host-switched to Caesalpinioideae (Fabaceae) (Delobel, 2006; 
Kergoat et al., 2007a; Di-Iorio, 2005; Tuda et al., unpublished). Group 5 shares with Clade I all the following species examined and thus can be concluded to be equivalent: Bruchidius aureus Arora, $B$. badjii Delobel, B. biloboscutus Pic, B. flavovirens Arora, B. lerui Delobel, B. lineolatus Arora, $B$. pygomaculatus Arora, B. saundersi (Jekel), B. solanensis Arora, B. sparsemaculatus Pic, B. terrenus (Sharp), B. urbanus (Sharp), and B. variegata Arora.

\section{ACKNOWLEDGMENTS}

This work was supported by Grant-in-Aids for Scientific Research (B)(17405005), (C)(19510237), and for Young Scientists (B)(15770011) from MESSC (MEXT) and JSPS. I thank K. Morimoto and A. Delobel for their valuable comments on an earlier version of the manuscript, S. Buranapanichpan for the assistance in the field investigation, C. Niyomdham for identification of plant specimens, and G.J. Kergoat for molecular information on African Bruchidius.

\section{REFERENCES}

Arora GL (1977) Taxonomy of Bruchidae (Coleoptera) of Northwest India. Part I. Adults. Orient Ins Suppl 7: 1-132

Arora GL (1980) A study of the biology and taxonomy of the genus Bruchidius (Coleoptera:

Bruchidae) from India. Final Technical Report (1974-1979), U.S. PL-480 Research Project

A7-ENT-103. Department of Zoology, Punjab University, Chandigarh

Borowiec L (1987) The genera of seed-beetles (Coleoptera, Bruchidae). Polsk Pismo Entomol 57:

Chûjô M (1937) Family Bruchidae, Class Insecta, Coleopteroidea-Coleoptera. Fauna Nipponica 10: 1-99 (In Japanese)

Delobel A (2006) Two new species of Bruchidius feeding on Caesalpinioids in Africa (Coleoptera: Bruchidae: Acanthoscelidini). Genus 17: 107-119

Delobel B, Delobel A (2006) Dietary specialization in European species groups of seed beetles (Coleoptera: Bruchidae: Bruchinae). Oecologia 149: 428-443

Di-Iorio OR (2005) An Asian species of Bruchinae (Coleoptera: Chrysomelidae) developing in the seeds of Gleditsia triacanthos L. (Caesalpiniaceae) in Argentina. Agrociencia 39: 327-337 Jermy T, Szentesi A (2003) Evolutionary aspects of host plant specialisation — a study on bruchids (Coleoptera: Bruchidae). Oikos 101: 207-215

Kergoat GJ, Delobel A, Fediere G, Le Ru B, Silvain JF (2005) Both host-plant phylogeny and 
chemistry have shaped the African seed-beetle radiation. Mol Phylogenet Evol 35: 602-611

Kergoat GJ, Silvain JF, Buranapanichpan S, Tuda M (2007a) When insects help to resolve plant phylogeny: evidence for a paraphyletic genus Acacia from the systematics and host-plant range of their seed-predators. Zool Scr 36: 143-152

Kergoat GJ, Silvain JF, Delobel A, Tuda M, Anton K-W (2007b) Defining the limits of taxonomic conservatism in host-plant use for phytophagous insects: molecular systematics and evolution of host-plant associations in the seed-beetle genus Bruchus Linnaeus (Coleoptera: Chrysomelidae: Bruchinae). Mol Phylogenet Evol 43: 251-269

Morimoto K (1990a) Bruchidius serricollis, a new species of Bruchidae from Japan (Coleoptera). ESAKIA, Spec Issue 1: 93-95

Morimoto K (1990b) A synopsis of the bruchid fauna of Japan. In "Bruchids and Legumes: Economics, Ecology and Coevolution” Ed by K Fujii, AMR Gatehouse, CD Johnson, R Mitchel, T Yoshida, Kluwer, Dordrecht, pp 131-140

Nielsen I (1985) The Malesian species of Acacia and Albizia (Leguminosae - Mimosoideae). Opera Bot 81: 1-50

Tuda M (2007) Applied evolutionary ecology of insects of the subfamily Bruchinae (Coleoptera: Chrysomelidae). Appl Entomol Zool 42: 337-346

Tuda M, Morimoto K (2004) A new species Megabruchidius sophorae (Coleoptera, Bruchidae), feeding on seeds of Styphnolobium (Fabaceae) new to Bruchidae. Zool Sci 21: 105-110

Tuda M, Chou L-Y, Niyomdham C, Buranapanichpan S, Tateishi Y (2005) Ecological factors associated with pest status in Callosobruchus (Coleoptera: Bruchidae): high host specificity of non-pests to Cajaninae (Fabaceae). J Stored Prod Res 41: 31-45

Tuda M, Ronn J, Buranapanichpan S, Wasano N, Arnqvist G (2006) Evolutionary diversification of the bean beetle genus Callosobruchus (Coleoptera: Bruchidae): traits associated with stored-product pest status. Mol Ecol 15: 3541-3551 


\section{Figure legends}

Figs. 1-5. Bruchidius paicus sp. nov. (1) Dorsal view of a male. Scale line: $1.0 \mathrm{~mm}$. (2) Antenna of a male. Scale line: $0.5 \mathrm{~mm}$. (3) Right hind leg. Scale line: $1.0 \mathrm{~mm}$. (4) Male genitalia: median lobe. Scale line: $0.1 \mathrm{~mm}$. (5) Male genitalia: lateral lobes. Scale line: $0.1 \mathrm{~mm}$.

1

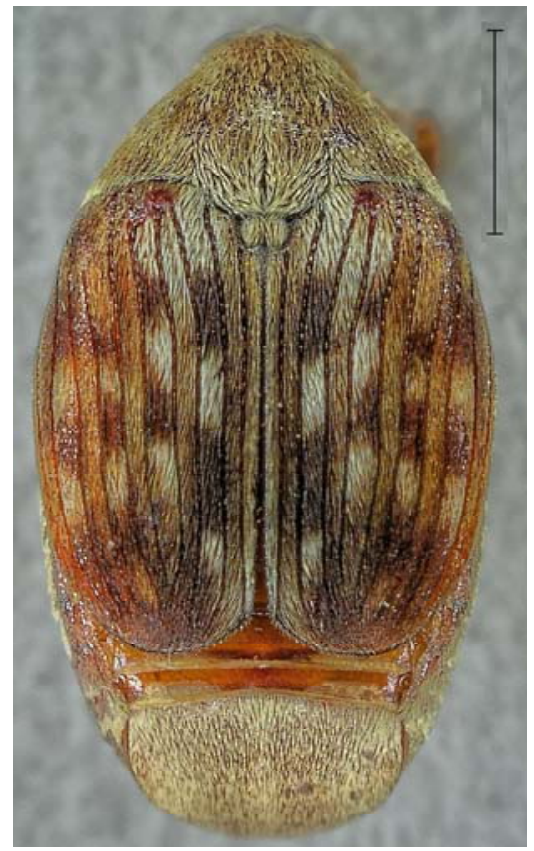

4

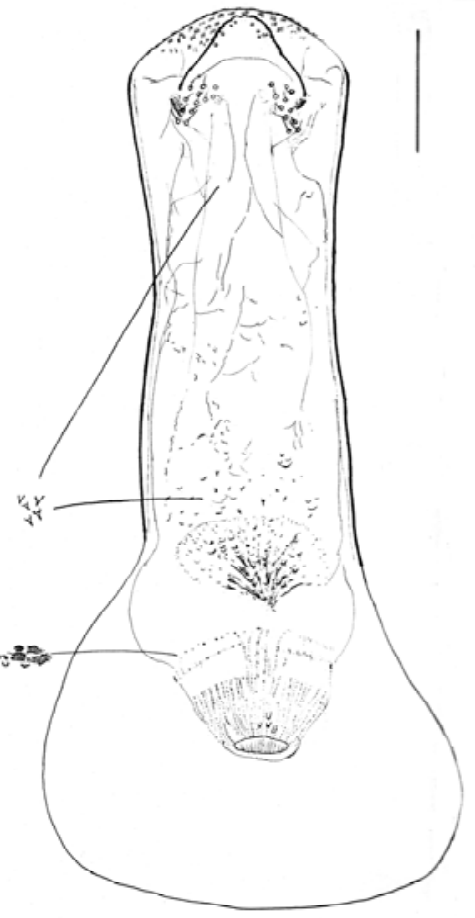

2

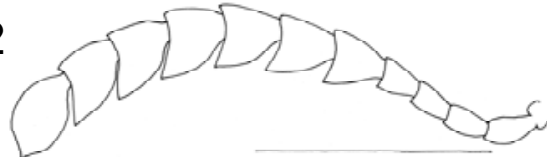

3

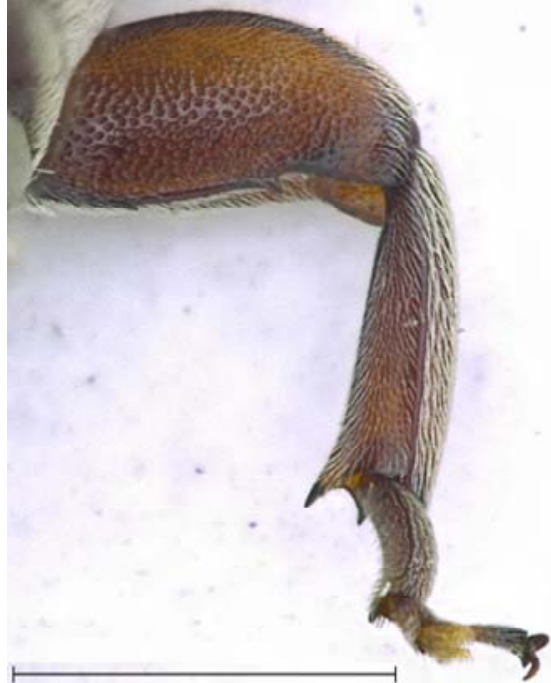

5

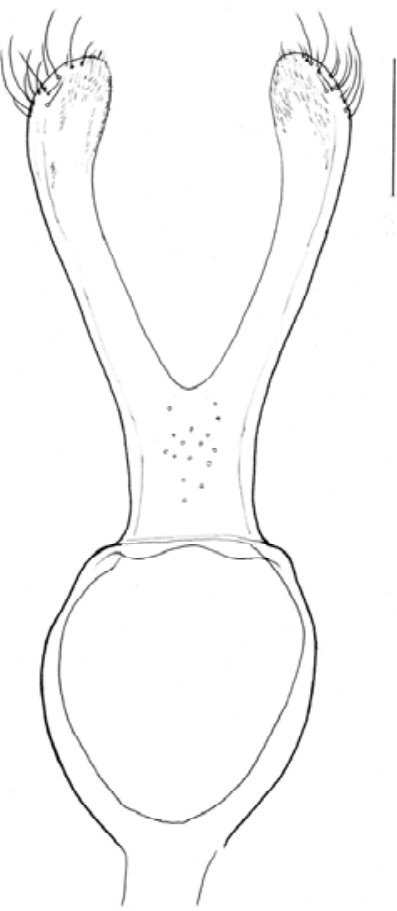

